\title{
PENGARUH METODE TALKING STICK DALAM PEMBELAJARAN \\ PKN TERHADAP PENDIDIKAN KARAKTER SISWA SMPN 6 SATU ATAP NGRAYUN KECAMATAN NGRAYUN KABUPATEN PONOROGO TAHUN PELAJARAN 2014/2015
}

\author{
Nurhadji Nugraha* \\ Wawan Kokotiasa** \\ Katminiatin Qomariah $^{* * *}$
}

\begin{abstract}
Abstrak
$\mathrm{P}$ enelitian ini bertujuan untuk mengetahui pengaruh metode talking stick dalam pembelajran PKn terhadap pendidikan karakter siswa kelas VIII SMPN 6 Satu Atap Ngrayun Kecamatan Ngrayun Kabupaten Ponorogo semester genap tahun pelajaran 2014/2015. Penelitian ini menggunakan pendekatan kuantitatif dengandesain One Groupposttest Design. Teknik pengambilan sampel yang digunakan adalah sampling purposive dengan metode pengumpulan data menggunakan angket, observasi, dan dokumentasi. Analisis data penelitian menggunakan statistik dengan rumus korelasi Product Moment.

Hasil penelitian menunjukkan bahwa ada pengaruh antara metode talking stick dalam pembelajaran PKn terhadap pendidikan karakter siswa kelas VIII Semester Gasal SMP N 6 Satu Atap Ngrayun Tahun Pelajaran 2014/2015. Sedangkan jika dilihat dari hasil penghitungan koefisien korelasi $r^{2}=0,98^{2}$. Hal tersebut menunjukkan hubungan yang kuat antara pembelajaran PKn dengan metode talking stick naik dan pendidikan karakter pada siswa.

Hasil analisis data berdasarkan penghitungan dengan menggunakan persamaan regresi ditemukan harga $a=7,73$ dan harga $b=1,18$, persamaan regresinya yaitu $\hat{Y}=7,73+1,18 \mathrm{X}$. . Hasil dari koefisien $\mathrm{b}$ menunjukkan angka positif, berarti apabila nilai atau harga $X$ pada variabel pembelajaran $P K n$ dengan metode talking stick naik, maka pendidikan karakter juga akan naik.
\end{abstract}

Kata Kunci: talking stick, pendidikan karakter

\footnotetext{
* Dosen Prodi PPKn IKIP PGRI Madiun

** Dosen Prodi PPKn IKIP PGRI Madiun

**** Mahasiswa Prodi PPKn IKIP PGRI Madiun
} 


\section{PENDAHULUAN}

Pendidikan memiliki peran penting dalam kehidupan yang dapat menunjang kelangsungan hidup manusia. Dewasa ini, banyak upayaupaya yang dilakukan untuk meningkatkan mutu pendidikan. Guru harus memiliki kemampuan dalam mengembangkan metode talking stick dan memanfaatkan media pembelajaran dalam menyajikan materi PKn menjadi lebih menarik dalam pembelajaran sehingga tujuan pembelajran yang diharapkan dapat dicapai dengan baik. Metode talking stick adalah metode yang sesuai dengan materi yang akan disampaikan, kondisi siswa, sarana dan prasarana yang tersedia serta tujuan pengajaranya.

Dalam situasi masyarakat yang selalu berubah, idealnya pendidikan tidak hanya berorientasi pada masa lalu dan masa kini, tetapi sudah seharusnya merupakan proses yang mengantisipasi dan membicarakan masa depan. Pendidikan hendaknya melihat jauh ke depan dan memikirkan yang akan dihadapi peserta didik di masa yang akan datang. Menurut Buchori (dalam Trianto 2007: 1), pendidikan yang baik adalah pendidikan yang tidak hanya mempersiapkan para siswanya untuk suatu profesi atau jabatan tetapi untuk menyelesaikan masalahmasalah yang dihadapinya dalam kehidupan sehari-hari.

Salah satu masalah pokok dalam pembelajaran pada pendidikan formal (sekolah) dewasa ini adalah masih rendahnya daya serap peserta didik. Hal ini tampak dari hasil belajar peserta didik yang senantiasa masih sangat memprihatinkan.

Mengajar merupakan suatu proses yang kompleks. Tidak hanya sekadar menyampaikan informasi dari guru kepada peserta didik. Banyak kegiatan maupun tindakan kelas dilakukan, terutama apabila menginginkan hasil belajar yang lebih baik pada seluruh peserta didik. Oleh karena itu, rumusan pengertian mengajar tidaklah sederhana. Artinya, membutuhkan rumusan yang dapat meliputi seluruh kegiatan dan tindakan dalam perbuatan mengajar itu sendiri.

Dalam keseluruhan proses pendidikan, kegiatan belajar dan mengajar merupakan kegiatan yang paling pokok. Hal ini berarti bahwa berhasil tidaknya pencapaian tujuan 
pendidikan banyak bergantung kepada proses belajar mengajar yang dirancang dan dijalankan secara profesional.

Setiap kegiatan belajar mengajar selalu melibatkan dua pelaku aktif, yaitu guru dan peserta didik. Guru sebagai pengajar merupakan pencipta kondisi belajar peserta didik yang didesain secara sengaja, sistematis dan berkesinambungan. Peserta didik sebagai subjek pembelajaran merupakan pihak yang menikmati kondisi belajar yang diciptakan guru.

Guru sebagai salah satu faktor pemegang peran yang sangat penting dalam pelaksanaan pembelajaran yang berusaha membantu mengembangkan potensi dan keterampilan siswa. Salah satu keberhasilan kegiatan belajar di sekolah ditentukan oleh pendidik atau guru melalui strategi mengajar yang diterapkan di kelas. Terkait dengan hal tersebut, guru dituntut mampu menyajikan pembelajaran yang bukan semata-mata hanya transfer ilmu, tetapi juga memberi wawasan dan keterampilan yang dapat meningkatkan kemandirian peserta didik.
Peran peserta didik tampak belum secara optimal diperlakukan sebagai subjek didik yang memiliki potensi untuk berkembang secara mandiri. Posisi peserta didik masih dalam situasi dan kondisi belajar yang menempatkan mereka dalam keadaan pasif, aktivitas belajar mengajar masih dominasi guru dalam menyampaikan informasi yang secara garis besar bahan-bahanya telah tertulis dalam buku paket.

Pendidikan di Indonesia diharapkan dapat mempersiapkan peserta didik menjadi warga negara yang memiliki komitmen kuat dan konsisten untuk mempertahankan Negara Kesatuan Republik Indonesia. Pendidikan Kewarganegaraan merupakan mata pelajaran yang memfokuskan pada pembentukan diri yang beragam dari segi agama, sosiokultural, bahasa, usia, dan suku bangsa. Pendidikan karakter merupakan suatu usaha yang disengaja untuk membantu seseorang sehingga dapat memahami, memperhatikan dan melakukan nilainilai etika yang inti.

Karakter merupakan perwujudan dari kehidupan yang direalisasikan melalui tindakan- 
tindakan yang benar berhubungan dengan diri seseorang dan orang lain. Masyarakat tampak mulai terusik dengan kondisi moralitas dan karakter yang tercermin dalam tindakan-tindakan para peserta didik yang menyimpang dari patron kebenaran dan etik.

Karakter adalah mustika hidup yang membedakan manusia dengan binatang. Orang-orang yang berkarakter kuat dan baik secara individual maupun sosial ialah mereka yang memiliki akhlak, moral, dan budi pekerti yang baik. Mengingat begitu urgennya karakter, maka institusi pendidikan memiliki tanggung jawab untuk menanamkannya melalui proses pembelajaran. Penguatan pendidikan karakter dalam konteks sekarang sangat relevan untuk mengatasi krisis moral yang sedang terjadi krisis yang nyata dan mengkhawatirkan dalam masyarakat dengan melibatkan milik kita yang paling berharga, yaitu anakanak. Agar pendidikan karakter dapat berjalan dengan baik diperlukan pemahaman yang cukup dan konsisten oleh seluruh personalia pendidikan. Di sekolah, kepala sekolah, pegawasan, guru, dan karyawan harus memiliki persamaan persepsi tentang pendidikan karakter bagi peserta didik. Kepala sekolah sebagai manajer harus mempunyai komitmen yang kuat tentang pendidikan karakter. Pendidikan karakter merupakan upaya untuk membantu perkembangan jiwa anakanak baik lahir maupun batin, dari sifat kodratinya menuju ke arah peradaban yang manusiawi dan lebih baik. Contohnya, anjuran atau suruhan terhadap anak-anak untuk duduk yang baik, tidak berteriakteriak agar tidak mengganggu orang lain, hormat terhadap orang tua, menyayangi yang muda, menghormati yang tua, menolong teman, dan seterusnya merupakan proses pendidikan karakter.

Karakter dapat didefinisikan sebagai panduan dari segala tabiat manusia yang bersifat tetap sehingga menjadi tanda yang khusus untuk membedakan orang yang satu dengan yang lain. Batasan ini menunjukkan bahwa karakter sebagai identitas yang dimiliki seseorang yang bersifat menetap sehingga seseorang atau sesuatu itu berbeda dari yang lain.

SMPN 6 Satu Atap Ngrayun Kecamatan Ngrayun Kabupaten 
Ponorogo merupakan lembaga pendidikan dasar di wilayah Kecamatan Ngrayun Kabupaten Ponorogo yang berlokasikan di daerah pegunungan. Lokasi di daerah pinggiran menjadikan SMPN 6 Satu Atap Ngrayun kurang terjangkau oleh kemajuan pendidikan, kemajuan pendidikan bidang pendidikan yang telah dirasakan oleh masyarakat perkotaan belum menjangkau sekolah ini sehinga dalam segala hal tentang pendidikan masih tertinggal jauh dibanding wilayah perkotaan. Dari segi tenaga pendidik juga demikian sehingga metode yang digunakan dalam pembelajaran masih konvensional dengan mengandalkan metode ceramah. Berbagai macam metode pembelajaran yang selama ini dikembangkan pemerintah belum diterapkan di sekolah ini sehingga dalam hal prestasi juga kalah bersaing dengan sekolah-sekolah di perkotaan. Selain itu, kemajuan pendidikan juga berdampak pada penanaman nilai karakter bangsa pada peserta didik. Nilai karakter bangsa yang seharusnya menjadi bekal peserta didik setelah lulus kelak belum dilaksanakan dalam proses pembelajaran.

\section{METODE PENELITIAN}

Penelitian ini menggunakan pendekatan kuantitatif dengan desain One Group posttest Design.. Teknik pengambilan sampel yang digunakan adalah sampling purposive dengan metode pengumpulan data menggunakan angket, observasi, dan dokumentasi. Analisis data penelitian menggunakan statistik dengan rumus korelasi Product Moment sedangkan untuk keabsahan data dilakukan dengan Uji Reabilitas dan Uji Homogenitas. Rumus korelasi product moment yaitu:

$$
r_{x y}=\frac{x y}{x^{2} y^{2}}
$$

Sedangkan untuk mengetahui linieritas variable $\mathrm{X}$ terhadap $\mathrm{Y}$ digunakan analisis regresi dengan persamaan : $\hat{Y}=a+b X$.

\section{HASIL DAN PEMBAHASAN}

Deskripsi penggunaan metode talking stick dengan menggunakan angket yang telah diberikan kepada 30 siswa dapat diperoleh data sebagai berikut : a) jumlah skor total $=1408$, b) Ratarata $=46,93$, c) Modus $=47$. d) 
Median $=49,17$, dan e) Standar deviasi sebesar 5,35.

Dari deskripsi di atas, setelah dianalisis menunjukkan bahwa dari 30 siswa yang mendapatkan nilai di atas rata-rata(> 46,93) sebanyak 19 orang atau 63\%, dan 11 orang atau $37 \%$ saja yang mendapat angka di bawah rata-rata. Artinya siswa antusiasme siswa biasa saja dalam mengikuti pembelajaran jika guru menggunakan metode talking stick.

Deskripsi data pendidikan karakter dengan angket yang telah diberikan kepada 30 siswa dapat dideskripsikan : a) jumlah skor total $=1884$, b) Rata-rata $=62,8$, c) Modus $=56$, d) Median $=61,5$, dan e) Standar deviasi sebesar 6,42 .

Dari deskripsi di atas, setelah dianalisis menunjukkan bahwa dari 30 siswa yang mendapatkan nilai di atas rata-rata(> 62,8) sebanyak 15 orang atau $50 \%$, demikian juga yang mendapat angka di bawah rata-rata sebesar 50\%. Artinya pendidikan karakter siswa yang baik bukan disebabkan oleh pembelajaran guru dengan menggunakan talking stick.

Untuk keperluan pengelompokkan hasil angket dari sampel tentang pelaksanaan pembelajaran PKn dengan talking stick ditetapkan menjadi empat kelas/interval yaitu baik, sedang, cukup, kurang dan sangat kurang. Rumus yang digunakan untuk menentukan lebar interval(i) adalah jarak pengukuran(R) dibagi jumlah kelas.

$$
\begin{aligned}
& i=R / k \\
R= & N \max -N \min \\
= & 57-36 \\
= & 21 .
\end{aligned}
$$

Jadi lebar kelas(i) $=21: 4=5$

Dari pengelompokkan tersebut disajikan hasil angket pembelajaran PKn dengan talking stick sebagaimana tercantum pada table 2 berikut.

Tabel 2. Interval Kelas Hasil Angket Mengenai Talking stick Siswa Kelas

\begin{tabular}{|c|c|c|c|c|}
\hline No & $\begin{array}{c}\text { Nilai } \\
\text { Interval }\end{array}$ & Kategori & F & $\begin{array}{c}\text { Prosentase } \\
\%\end{array}$ \\
\hline 1 & $52-56$ & Baik & 7 & $23,3 \%$ \\
\hline 2 & $47-51$ & Sedang & 12 & $40 \%$ \\
\hline 3 & $42-26$ & Cukup & 4 & $13,3 \%$ \\
\hline 4 & $37-41$ & Kurang & 7 & $23,3 \%$ \\
\hline \multicolumn{3}{|c|}{ Jumlah } & 30 & 100 \\
\hline
\end{tabular}
VIIISMPN 6 Satu Atap Ngrayun Semester Gasal Tahun Pelajaran 2014/2015

Berdasarkan perhitungan data diatas, dapat dikatakan bahwa pendidikan karakter siswa kelas VIII 
SMP N 6 Satu Atap Ngrayun tahun pelajaran 2014/2015 cukup. Hal ini terbukti dari 30 siswa $23,3 \%$ berkategori baik, $40 \%$ berkategori sedang, $13,3 \%$ berkategori cukup, $23,3 \%$ berkategori kurang.

Untuk keperluan pengelompokkan hasil angket dari sampel tentang peendidikan karakter ditetapkan menjadi empat kelas/interval yaitu baik, sedang, cukup, kurang dan sangat kurang. Rumus yang digunakan untuk menentukan lebar interval(i) adalah jarak pengukuran(R) dibagi jumlah kelas.

$$
\begin{aligned}
\mathrm{i} & =\mathrm{R} / \mathrm{k} \\
\mathrm{R} & =\mathrm{N} \max -\mathrm{N} \min \\
& =72-52=20 .
\end{aligned}
$$

Jadi lebar kelas(i) $=20: 4=5$

Dari pengelompokkan tersebut disajikan hasil pendidikan karakter sebagaimana tercantum pada table 3 berikut.

Tabel 3. Interval Kelas Hasil Angket Mengenai pendidikan karakter Siswa Kelas VIII SMPN 6 Satu Atap Ngrayun Tahun Pelajaran 2014/2015

\begin{tabular}{|l|l|l|l|l|}
\hline No & $\begin{array}{l}\text { Nilai } \\
\text { Interval }\end{array}$ & Kategori & F & $\begin{array}{l}\text { Prosen- } \\
\text { tase \% }\end{array}$ \\
\hline 1 & $67-72$ & Baik & 12 & $40 \%$ \\
\hline 2 & $62-66$ & Sedang & 3 & $10 \%$ \\
\hline 3 & $57-61$ & Cukup & 8 & $26,6 \%$ \\
\hline
\end{tabular}

\begin{tabular}{|l|l|l|l|l|}
\hline 4 & $52-56$ & Kurang & 7 & $23,3 \%$ \\
\hline \multicolumn{2}{|l|}{ Jumlah } & 30 & 100 \\
\hline
\end{tabular}

Berdasarkan perhitungan data di atas, dapat dikatakan bahwa pendidikan karakter siswa kelas VIII SMP N 6 Satu Atap Ngrayun tahun pelajaran 2014/2015 adalah kurang. Hal ini terbukti dari 30 siswa $40 \%$ berkategori baik, $10 \%$ berkategori sedang, 26,6\% berkategori cukup, $23,3 \%$ berkategori kurang.

Untuk mencari hubungan antara metode talking stick dalam pembelajaran PKN terhadap pendidikan karakter digunakan korelasi product moment.

$$
\begin{aligned}
& \mathrm{xy}=1007 \\
& x^{2}=858 \\
& y^{2}=1237
\end{aligned}
$$

$$
r_{x y}=\frac{x y}{x^{2} y^{2}}
$$

$$
r_{\mathrm{xy}}=\frac{1007}{\overline{8581237}}
$$

$$
r_{\mathrm{xy}}=\frac{1007}{\overline{1061346}}
$$

$$
\begin{aligned}
& r_{x y}=\frac{1007}{1030,22} \\
& r_{x y}=0,98
\end{aligned}
$$


Hal tersebut menunjukkan hubungan antara metode talking stick dalam pembelajaran PKN terhadap pendidikan karakter sangat kuat.

Sedangkan untuk mengetahui linieritas variable $\mathrm{X}$ terhadap $\mathrm{Y}$ digunakan analisis regresi. Berdasarkan penghitungan data yang ada, diperoleh:

$$
\begin{aligned}
N & =30 \\
\sum X & =1408 \\
\sum Y & =1884 \\
\sum X^{2} & =66940 \\
\sum Y^{2} & =119552 \\
\sum X Y & =89.429
\end{aligned}
$$

Untuk memperoleh nilai a dibutuhkan rumus sebagai berikut.

$$
\begin{gathered}
a=\frac{Y)\left(\sum X^{2}-\left(\sum X\right)\left(\sum X Y\right)\right.}{n \sum X^{2}-\left(\sum X\right)^{2}} \\
a a=\frac{1884(66940)-1408(89429)}{30(66940)-(1408)^{2}} \\
a=\frac{126114940-125916032}{2008200-1982464} \\
a=\frac{198908}{25736} \\
a=7,73 \\
\text { Selanjutnya ialah mencari } \\
\text { nilai koefisiensi b, nilai koefisiensi } \\
\text { dari data di atas sebagai berikut. }
\end{gathered}
$$

$$
\mathrm{b}=\frac{n \sum X Y-\left(\sum X\right)\left(\sum Y\right)}{n \sum X^{2}-\left(\sum X\right)^{2}}
$$

$\mathrm{b}=\frac{30(89429)-(1408)(1884)}{30(66940)-(1408)^{2}}$

$$
\mathrm{b}=\frac{2682870-2652672}{2008200-1982464}
$$

$$
\begin{aligned}
& \mathrm{b}=\frac{30198}{25736} \\
& \mathrm{~b}=1,18
\end{aligned}
$$

Selanjutnya memasukkan nilai-nilai tersebut ke dalam rumus persamaan regresi $\hat{Y}=a+b X$.

$$
\begin{aligned}
& \hat{Y}=a+b X \\
& \hat{Y}=7,73+1,18 X .
\end{aligned}
$$

Koefisien $\mathrm{b}$ disebut sebagai koefisien arah regresi linier dan menyatakan perubahan rata-rata variabel $\mathrm{Y}$ untuk setiap perubahan variabel $X$ sebesar nilai satu unit. Perubahan ini menunjukkan pertambahan nilai karena $b$ bertanda positif. Hasil penghitungan, diperoleh $\mathrm{b}=1,18$ bertanda positif. Artinya, setiap kali variabel $\mathrm{X}$ (metode talking stick pembelajaran $\mathrm{PKN}$ ) bertambah satu maka rata-rata variabel $\mathrm{Y}$ (pendidikan karakter) bertambah 1,18. Jadi, ada pengaruh antara metode talking stick dalam pembelajaran PKN terhadap pendidikan karakter siswa SMPN 6 
Satu Atap Ngrayun Kecamatan Ngrayun Kabupaten Ponorogo Tahun Pelajaran 2014/2015.

Pengujian instrumen dalam penelitian ini terdiri dari uji validitas danuji reliabilitas. Pengujian validitas dan reliabilitas instrumen penelitian sebagai berikut:

a. Hasil uji validitas

Perhitungan untuk uji validitas angket talking stick menunjukkan bahwa semua item soal dalam angket adalah valid.Item soal dalam angket dinyatakan valid karena $r_{\text {hitung }}$ lebih besar dari nilai $r_{\text {tabel }}$ pada taraf signifikan 0.05 yaitu 0.361 dengan N 30. Artinya, semua item soal dalam variabel talking stick dapat dipercaya untuk mengambil data penelitian.

b. Hasil uji reliabilitas

Uji reliabilitas dilakukan dengan koefisien alpha (a) dari cronbach dengan menggunakan alat bantu program Microsoft Word Excel. Hasil uji reliabilitas pada angket talking stick dapat dilihat pada tabel dibawah ini:

Tabel 4.HasilUji Reliabilitas Angket talking stick

\begin{tabular}{|c|c|c|c|}
\hline Angket & $\mathrm{r}_{\text {hitung }}$ & $\begin{array}{c}\mathrm{r}_{\text {tabel }} \\
(0.05: 38)\end{array}$ & Keterangan \\
\hline $\begin{array}{c}\text { Talking } \\
\text { stick }\end{array}$ & 0.734 & 0.361 & Reliabel \\
\hline
\end{tabular}

Hasil uji reliabilitas angket

talking stick terhadap pendidikan karakterdengan $r_{\text {tabel }}$ yaitu sebesar 0.361. Karena pada ketiga angket tesebut terlihat bahwa $r_{\text {hitung }}>$ $\mathrm{r}_{\text {tabel}}$, dapat disimpulkan bahwa ketiga angket tersebut adalah reliabel.

\section{KESIMPULAN}

Berdasarkan hasil penelitian yang dilakukan, dapat ditarik kesimpulan bahwa pembelajaran PKn kelas VIII SMP N 6 Satu Atap Ngrayun tahun pelajaran 2014/2015 adalah cukup. Hal ini terbukti dari 30 siswa $6,25 \%$ berkategori baik sekali, $23,3 \%$ berkategori baik, $40 \%$ berkategori sedang, $13,3 \%$ berkategori cukup, 23,3\% berkategori kurang.

Pendidikan Karakter siswa kelas VIII SMP N 6 Satu Atap Ngrayun tahun pelajaran 2014/2015 adalah kurang. Hal ini terbukti dari 30 siswa $40 \%$ berkategori baik, $10 \%$ berkategori sedang, 26,6\% berkategori cukup, 23,3\% berkategori kurang. 


\begin{abstract}
Hasil pengujian hipotesis dengan menggunakan rumus $r$ product moment diperoleh koefisien korelasi sebesar 0,98 yang berarti ada hubungan yang signifikan antara Pembelajaran PKn terhadap pendidikan karakter siswa kelas VIII SMP N 6 Satu Atap Ngrayun tahun pelajaran 2014/2015. Sedangkan linieritas variable $\mathrm{X}$ terhadap $\mathrm{Y}$ diperoleh persamaan regresi $\hat{Y}=$ $7,73+1,18 \mathrm{X}$.
\end{abstract}

Hal ini terbukti bahwa pendidikan karakter dipengaruhi oleh pembelajaran PKn dengan menggunakan metode talking stick. 


\section{DAFTAR PUSTAKA}

Agus Suprijono. 2013 Cooperative Learning. Yogyakarta.

Miftahul Huda. 2013 Model-model

Pengajaran dan

Pembelajaran. Yogyakarta.

Muchlas Samani. 2011 Pendidikan Karakter. Bandung: PT Remaja Rosdakarya.

Mulyasa.2012 Manajemen Pendidikan Karakter. Jakarta: PT Bumi Aksara.

Sigit Mangun Wardoyo.2013 Pembelajaran

Konstruktivisme Teori dan Aplikasi Pembelajaran dalam Pembentukan Karakter. Bandung.

Sugiyono. 2012 Metode Penelitian Pendidikan Pendekatan Kualitatif, Kuantitatif, dan $R \& D$. Bandung.

Suharsimi Arikunto. 2010 Prosedur Penelitian Suatu Praktik. Jakarta.

Trianto.2007 Model-model Pembelajaran Inovatif Berorientasi Konstruktivistik. Jakarta.

Zainal Aqib. 2013 Model-model, Media, dan Strategi Pembelajaran Kontekstual (Inovatif). Bandung. 